\title{
ON THE RELATIONSHIP BETWEEN WATER QUALITY AND SUNLIGHT UV-RAYS VOLUME AT RESERVOIR
}

\section{Akira HIRATSUKA * Yasunori FUKUDA** and Seiyo SHIGEMITSU*}

\begin{abstract}
Destruction of the ozonosphere (formation of ozone holes) has recently been recognized as one of the global environmental problems, because the increase of ozone holes causes an increase of ultraviolet radiation pouring onto the surface of the earth. The ultraviolet radiation may have a serious influence on cells or genes of human beings, and may also become a factor which gives rise to the increase of skin cancer. A counterplan must be formulated in a great hurry ${ }^{1)}$. We reported the sunlight UV-rays volume in the atmosphere measured for periods of 4 month(May-August,1993) ${ }^{2}$. We think, on the other hand, to investigate the variation of water quality at reservoir in connection with UV-rays volume is also very important. This paper examines an estimation of the sunlight UV-rays volume using TLD and centering on the relationship between the water quality and sunlight UV-rays volume in the water for a fixed period time. The contents are as follow:(1) It was recognized that the measurement of sunlight UV-rays volume in the water is possible, and the peak of $\left(\mathrm{PO}_{4}\right)^{3-}$ corresponding to the depth of water in the relationship between the UV-rays volume and $\left(\mathrm{PO}_{4}\right)^{3-}$ exists. (2)The relationship between the sunlight UV-rays volume and the water qualities (TN/TP) measured for the period of 5 months (Jul Nov.1994) is represented (3) Experimental procedure result and (Jul.-Nov., 1994) examination are mentioned, and relationships between the sunlight UV-rays volume and $\left(\mathrm{PO}_{4}\right)^{3-}$ ion in connection with optimal UV-rays volume for aquatic life at reservoit are considered. The obtained data is accord with the other data ${ }^{3)}$.
\end{abstract}

KEYWORDS; sunlight UV-rays volume, TLD (Thermoluminescence dosimeter) water quality, reservoir

\section{INTRODUCTION}

In recent years, destruction of the ozone layer as one of the global enviromental issues has been noticed. Ozone layer protects the whole life (including aquatic organism/plant etc. at reservoir) on the earth from the harmful sunlight UV-rays. It is known that if sunlight UV-rays pours on the ground a photosynthesis of plants is restrained and a gene structure material of the human body is destroyed.

We conducted an estimation of sunlight UV-rays volume by the TLD after conducting

* Dept. of Civil Eng., Osaka Sangyo Univ., Osaka, 574 Japan.

** Dept. of Lib. Arts, Osaka Sangyo Univ., do. 
the measurement using that for periods of 4 months(May-August,1993). However, it is open to question in view of the practical use,especially in the polluted water such as reservoirs and lakes.

In order to investigate the variation of water quality at reservoir in connection with sunlight UV-rays volume, this paper examines an estimation of the sunlight UV-rays volume using TLD and centering the relationship between the water quality and sunlight UV-rays volume in the reservoir for a fixed period time.

\section{EXPERIMENTAL}

The samples were prepared by the solid state reaction. The starting materials, $\mathrm{CaF}_{2}$ (purity 99.99\%) and $\mathrm{Tb}_{4} \mathrm{O}_{7}(99.99 \%)$ were mixed in the desired ratio and pressed into the pellets ( diameter: $\fallingdotseq 7 \mathrm{~mm}$; thickness: $0.7 \mathrm{~mm}$ ). The mixture was heated at $1100^{\circ} \mathrm{C}$ for $5 \mathrm{hrs}$ in the air. The $\operatorname{TLD}\left(\mathrm{CaF}_{2}: \mathrm{Tb}\right)$ attached on the sample holder of a receptacle which was made of quartz. This receptacle kept at the surface layer of the reservoir. In order to examine the relationship between the $\mathrm{TL}$ intensity and exposure time, the areas in the temperature range from 152 to $242{ }^{\circ} \mathrm{C}$ of the $\mathrm{TL}$ glow curves were plotted against the exposure. Figure 1 shows the relation-ship between TL intensity and exposure time to the sunlight. The $\mathrm{TL}$ observed after the exposure to the sunlight is considered to be due to the UV radiation included in the sunlight.

Figure 2 shows the dependence of the irradiation wavelength on TL intensity. The TL excitation peak was located near $235 \mathrm{~nm}$, and TL was not observed when the excitation wavelength was longer than $320 \mathrm{~nm}$. The TL excitation seems to be related to the optical excitation band near $240 \mathrm{~nm}$. Therefore, the material $\left(\mathrm{CaF}_{2}: \mathrm{Tb}_{4} \mathrm{O}_{7}\right)$ we used as a sensor for measuring the UV-rays volume may be used for UV-C and UV-B dosimeters. However, the sensitivity of TLD in UV-B region is very weak compared with that of TLD in UV-C region. In actual measurement, therefore, it may be necessary to expose the material to the sunlight UV-rays more than $0.5 \mathrm{hr}^{2}$.

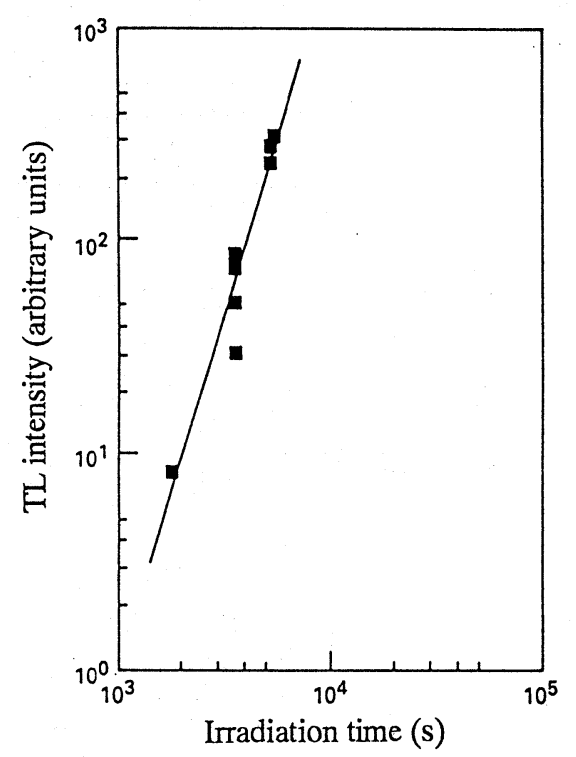

Fig.1 Relationship between TL intensity and sunlight exposure time. TL intensity was integrated from 152 to $242^{\circ} \mathrm{C}$.

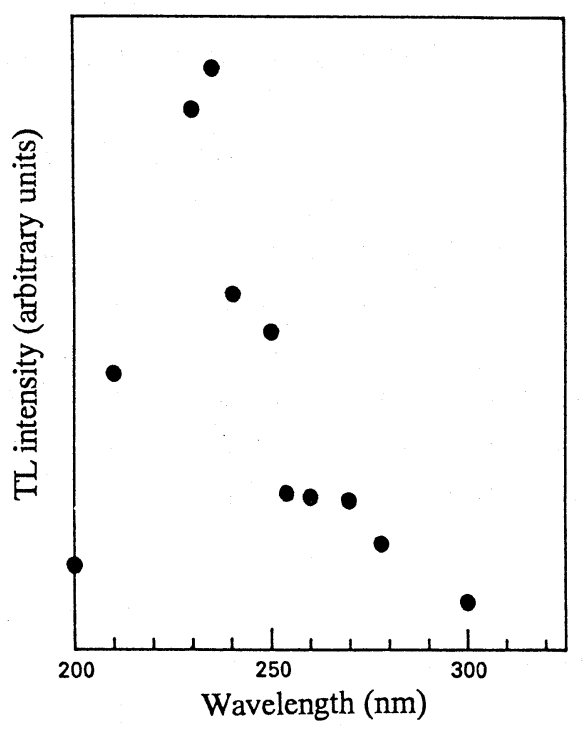

Fig.2 TL excitation spectrum of $\mathrm{CaF}_{2}: \mathrm{Tb}_{4} \mathrm{O}_{7}(0.006 \mathrm{wt} \%)$. 


\section{RESULTS AND DISCUSSION}

We select a reservoir for investigating the variation of water qualities in connection with the sunlight UV-rays volume. The examined reservoir has some waste water inflow.

Figure 3 shows the relationship between the sunlight UV-rays volume and the TN. at the reservoir. It can be seen from Fig. 3 the UV-rays volume becomes significantly greater in the surface layer, and vice versa.

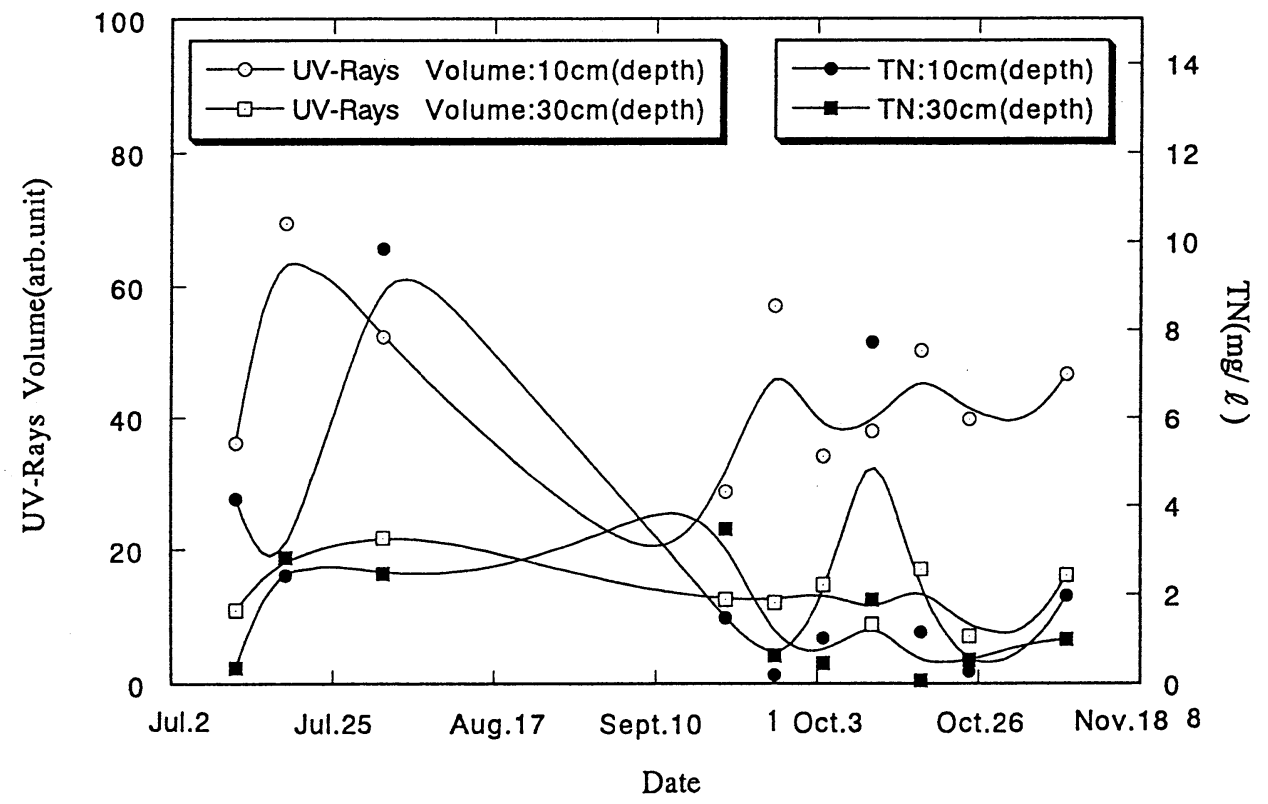

Fig.3. Relationship between UV-Rays volume and TN at the reservoir .

Figure 4 shows the relationship between the sunlight UV-rays volume and the TP at the reservoir. It can be seen from Fig. 4 that the TP also shows the same tendency as the TN mentioned above. However, the TP shows a marked tendency in comparison with the TN in the relationship between the sunlight UV-rays volume and the water qualities(TN/TP). The TP at a depth of $30 \mathrm{~cm}$ is much larger than that at $10 \mathrm{~cm}$. It is thought that the phenomena may markedly affect the life (such as a plankton) living in the reservoir. From the obtained data, the possibility of the forecasting with respect to the water qualities by means of the monitoring of the UVrays volume was suggested. In this connection, as the transparency of water was a little bit very high, it is considered that the growing of a aquatic life such as algae was not appreciably observed in the reservoir.

Figurer 5 shows the relationship between the sunlight UV-rays volume and $\left(\mathrm{PO}_{4}\right)^{3-}$ at the reservoir. We recognized the presence of the peak of $\left(\mathrm{PO}_{4}\right)^{3-}$ corresponding to the depth of water in the relationship between the two. The peak were located at about 10 arb.unit for $30 \mathrm{~cm}$ in depth and 40 arb.unit for $10 \mathrm{~cm}$. It seems from this point of view that the optimal UV-rays volume is needed to increase $\left(\mathrm{PO}_{4}\right)^{3-}$. It is also described that the optimal UV-rays volume is required for the aquatic life(such as a plankton) in the reservoir. 


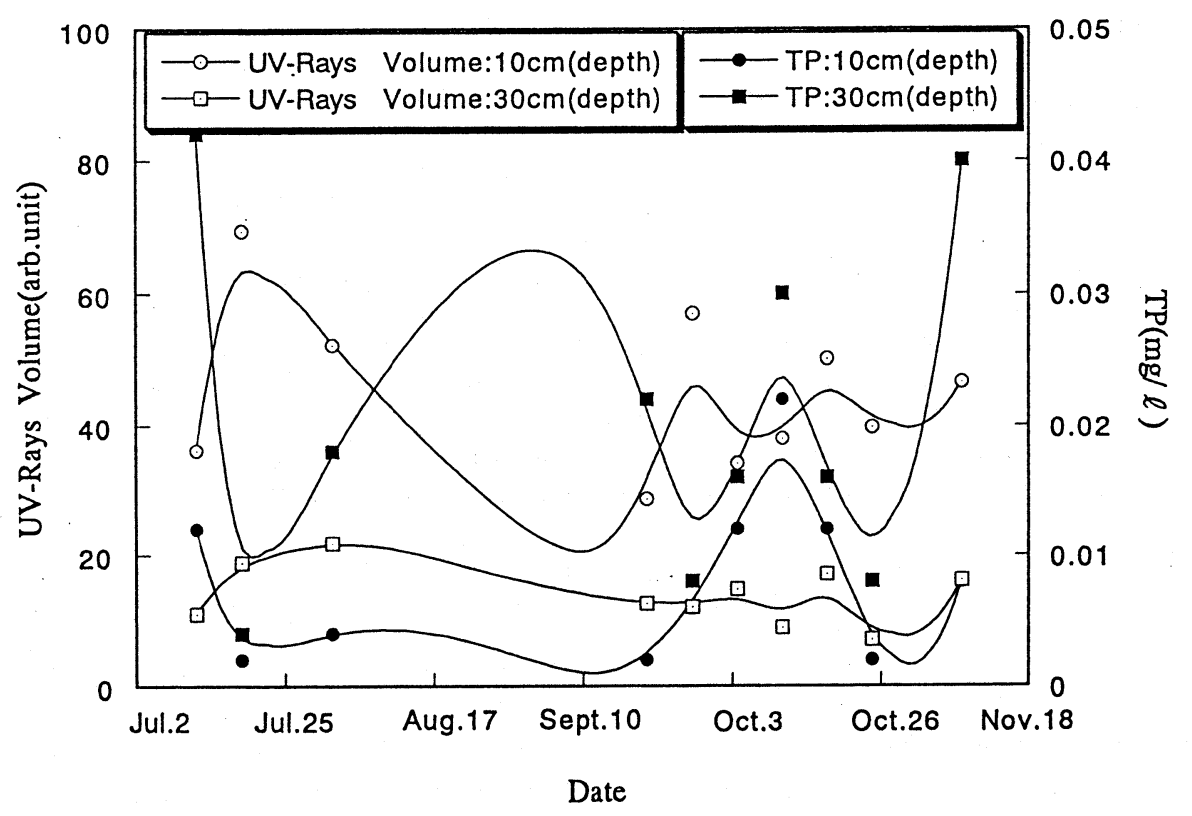

Fig.4. Relationship between UV-Rays volume and TP at the reservoir .

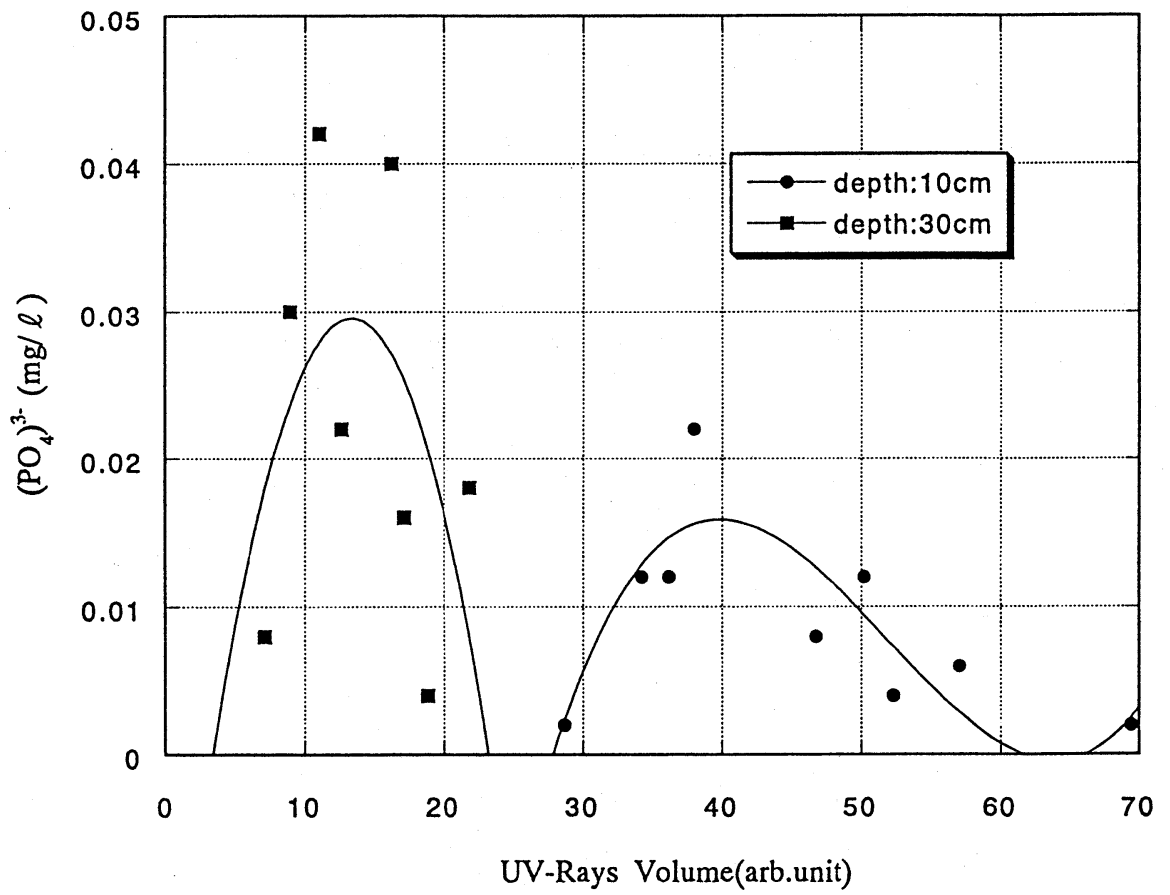

Fig.5. Relationship between UV-Rays volume and $\left(\mathrm{PO}_{4}\right)^{3-}$ at the reservoir . 
Table 1 shows the TL intensity for the past two years. Figure 6 shows the seasonal change of TL intensity measured in both atmosphere and water for the past two years. It can be seen from the figure the seasonal change of the TL intensity is very clear, and the difference of the TL intensity for the past two years, especially over a period of May-Aug. is also obvious. The data we obtained this time is in accord with the other data $^{3)}$.

Figure 7 shows the TL intensity measured in $t$ he water in 1994. It can be seen from

the figure the value of TL intensity due to the difference of depth of water is very clear.
Table 1. TL Intensity(arb.unit)

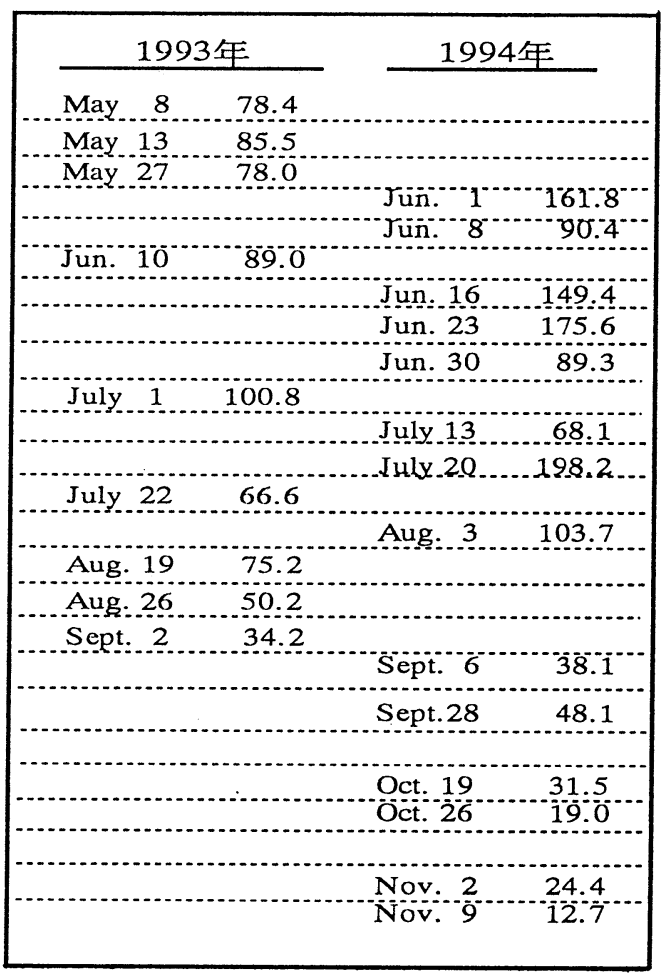

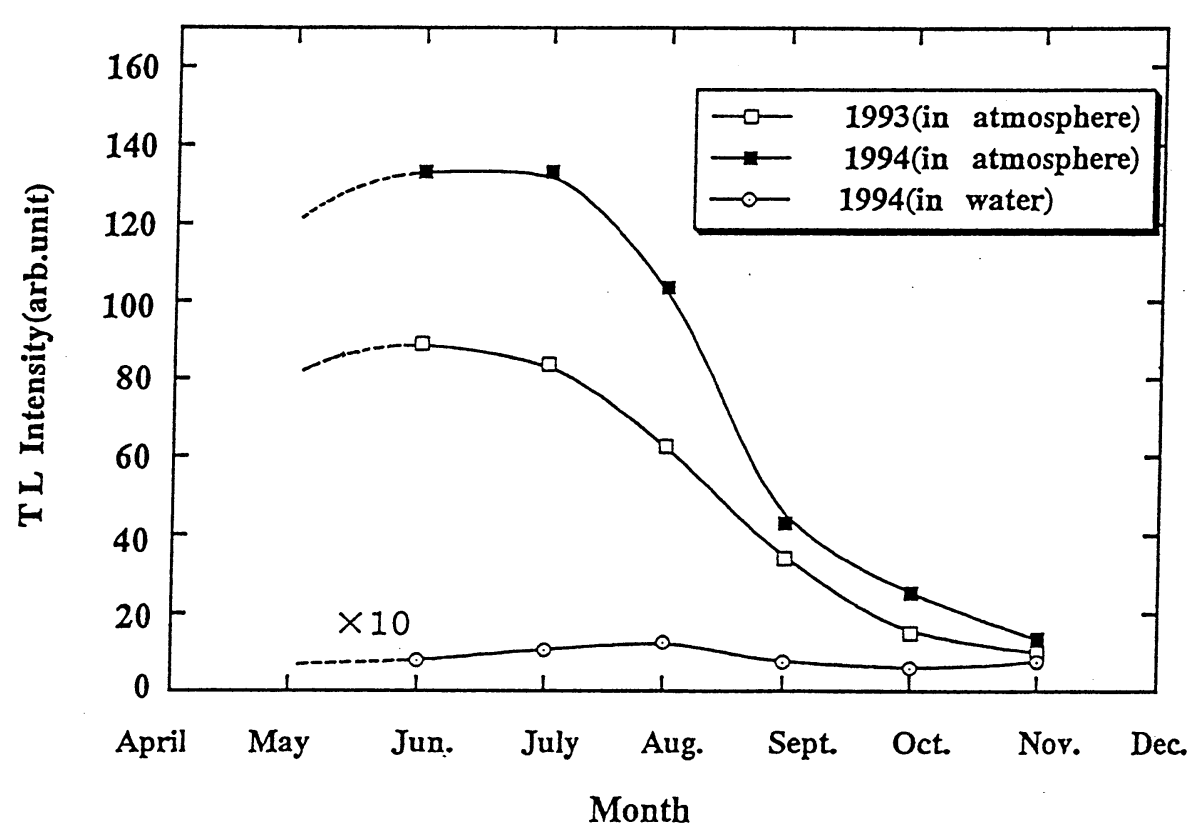

Fig.6. Seasonal change of TL Intensity. 


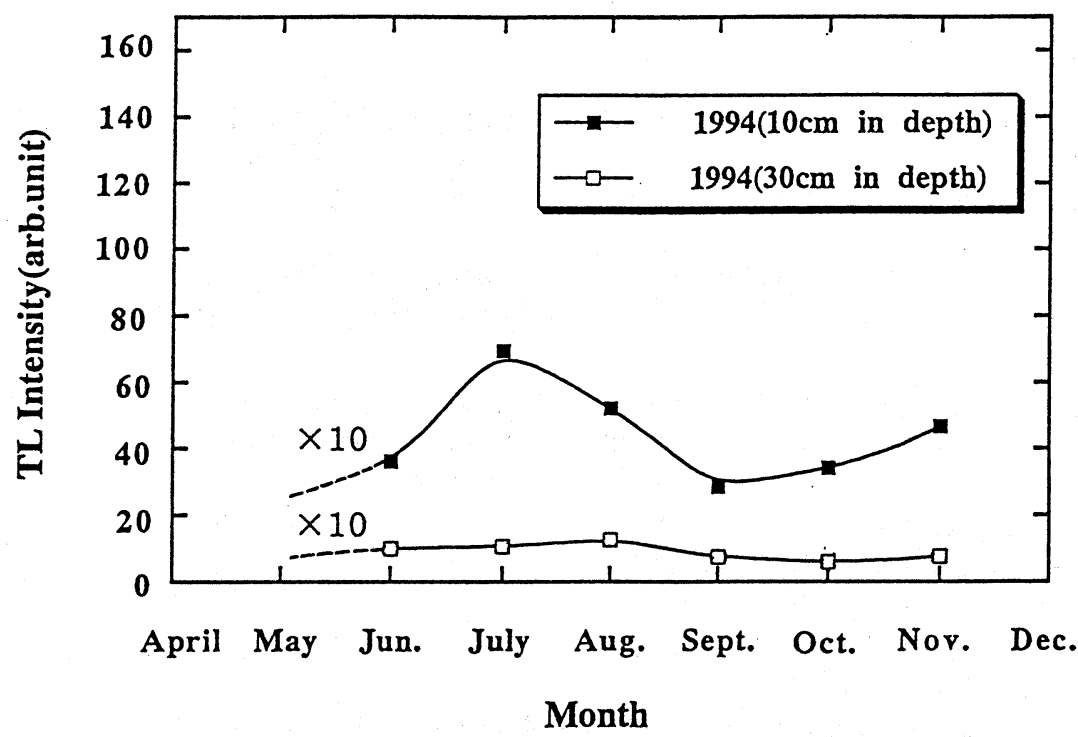

Fig.7. TL Intensity due to the difference of depth of water.

\section{CONCLUSION}

The possibility of the forecasting with respect to the water quality by means of the monitoring of the UV-rays volume was suggested.

The presence of the peak of $\left(\mathrm{PO}_{4}\right)^{3-}$ corresponding to the depth of water in the relationship between the UV-rays volume and $\left(\mathrm{PO}_{4}\right)^{3-}$ was recognized. The peak were located at about 10 arb.unit for $30 \mathrm{~cm}$ in depth and 40 arb.unit for $10 \mathrm{~cm}$ at the reservoir. It is suggested from this point of view that the optimal UV-rays volume is needed to increase $\left(\mathrm{PO}_{4}\right)^{3-}$. It is also described that the optimal UV-rays volume is required for the aquatic life (such as a plankton) in the reservoir.

The obtained data this time is accord with the other data ${ }^{3)}$ which shows theseasonal change of UV-B. Therefore, it is suggested that the data actually shows the monitoring of UV-B.

We will try to study the relationship between UV-B and aquatic life as a subject for further discussion in the near future.

\section{REFERENCES}

1)H.Ohtaki, H.Kido, A.Hiratsuka, Y.Fukuda and N.Takeuchi: J. Mater. Sci., Lett., 13 (1994), 1267.

2)A.Hiratsuka and Y.Fukuda: Environmental Systems Research, 22 (1994) 383.

3)Environment Agency Government of Japan. Quality of the environment in Japan 1993,

Stratospheric Ozone, Chlorofluorocarbon. 15-20 (1995). 